\title{
A case of pulmonary embolism with rare unusual presentation of syncope
}

\author{
Rajeev Srivastava, Avneesh Prasad, Shivum Bharadwaj, L C Gupta
}

National heart institute New Delhi India

Corresponding Author: Rajeev Srivastava

Cardiology, National heart institute New Delhi India

Email: rajeev.srivastava40@yahoo.com

Cite this article as: Srivastava R, Prasad A, Bharadwaj S et.al. A case of pulmonary embolism with rare unusual presentation of syncope Nepalese Heart Journal 2018; 15(2): 41-42.

Received date: $29^{\text {th }}$ June 2018

Accepted date: $19^{\text {th }}$ August 2018

\section{Abstract}

Presentation in pulmonary embolism may be variable and each patient should be thoroughly investigated including young patients. Other non-conventional presentation and risk factors should also be assessed. Appropriate management should be considered for this life threatening disease in hospital and follow up with anticoagulants is necessary for prevention of recurrences.

DOI: http://dx.doi.org/10.3126/njh.v15i2.21477

\section{Abbreviations:}

PASP: pulmonary artery systolic pressure. NOAC: nonvitamin $\mathrm{K}$ antagonist oral anticoagulants. STK: streptokinase. V; Q: ventilation/perfusion.

\section{Case report:}

We present a case of young 38-year-old gentleman presented with complaints of an episode of syncope. On examination extremities were cold with blood pressure of $90 / 60 \mathrm{~mm} \mathrm{Hg}$ and ECG revealed sinus tachycardia. Troponin $\mathrm{T}$ was done which was found to be positive. Echocardiography done revealed dysfunction of right side of heart with PASP $54 \mathrm{mmHg}$ and high resistant flow in pulmonary artery. Subsequently venous lower limb Doppler was done which revealed soft clot in left superficial femoral vein (SFV) and popliteal vein. Also, V: Q scan done which revealed massive pulmonary embolism. Due to absence of conventional risk factors for thromboembolism in our patient, other risk factors were investigated in which homocysteine level was $41 \mathrm{umol} / \mathrm{L}$, which was elevated. In the view of acute massive pulmonary embolism with shock, he was thrombolysed with STK 2.5 lakh international units bolus followed by infusion at the rate of 1lakh International unit per hour. Echocardiography done after 12 hrs revealed reduced PASP $25 \mathrm{mmhg}$, better right ventricular function and marked clinical improvement. Heparin was continued. Finally, Patient was discharged on non-vitamin K antagonist oral anticoagulants (NOAC), Dabigatran, and advised for routine follow up.

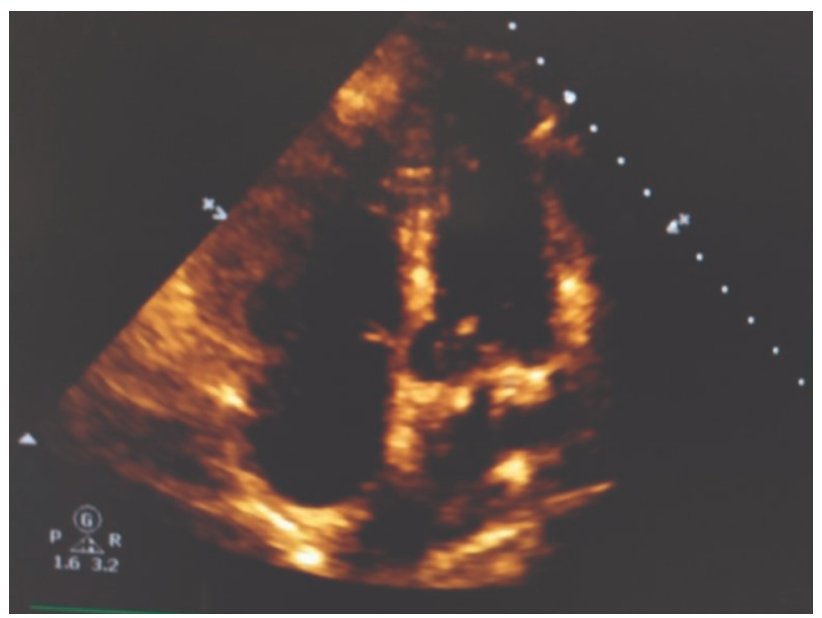

Fig 1: $2 \mathrm{D}$ ECHO :4 chamber view dilated Right atrium/Right ventricle 


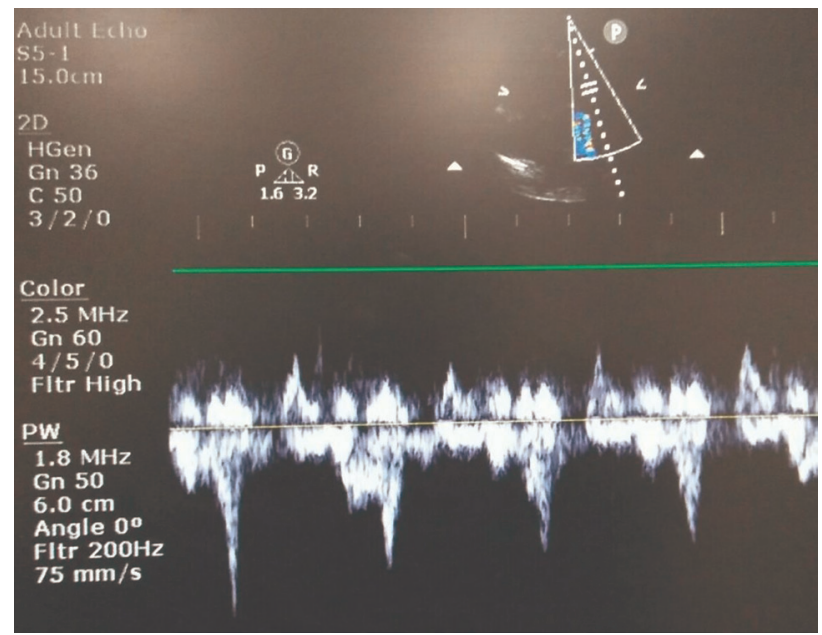

Fig 2: Doppler showing high resistant flow across pulmonary artery

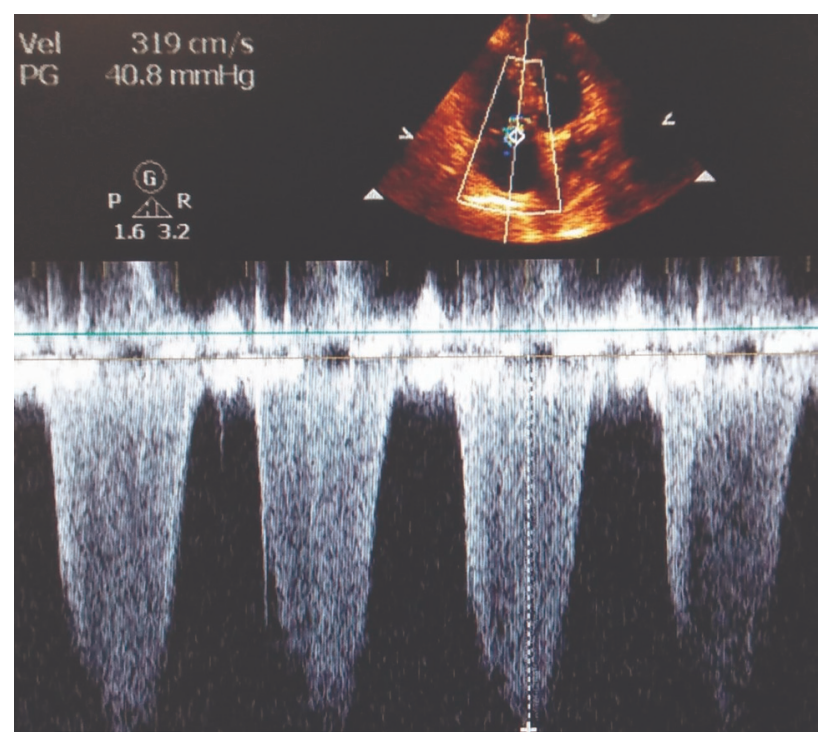

Fig 3: Elevated pulmonary artery pressures as measured by Continuous Wave doppler.

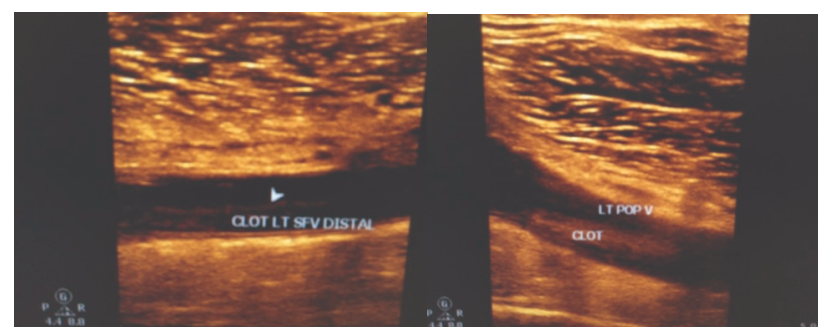

Fig 4-5: Lower limb venous Doppler showing clot in left superficial femoral vein and left popliteal vein

\section{Discussion}

Pulmonary thromboembolism is a potential fatal disease with clinical presentation ranging from unstable state to silent disease. The classical symptoms of acute pulmonary embolism include chest pain, dyspnea and hemoptysis. Syncope is an atypical symptom of pulmonary embolism as initial presentation ${ }^{1-5}$. Syncope seems to be related to central and or massive pulmonary embolism. Three major and pathophysiological mechanisms proposed for development of syncope in acute pulmonary embolism are acute heart failure, unstable dysrhythmia and vasovagal reflex. Occlusion of $>50 \%$ of pulmonary vascular bed can cause right ventricle (RV) Failure, impaired left ventricular filling, tachycardia, hypotension and reduced cerebral perfusion. In daily practice, Troponin- $T$ is used to diagnose acute coronary syndrome. However, positive results may also be found in pulmonary embolism, heart failure, myocarditis, cardiomyopathies, renal failure and sepsis. ${ }^{6}$ In addition, the patient was found to have high homocysteine levels making him high risk for deep vein thrombosis ${ }^{7}$. In our patient venous Doppler revealed soft clot in left SFV and popliteal vein with consequent massive pulmonary embolism. Pulmonary CT angiogram was not done because patient was symptomatic with unstable hemodynamics. We further took decision to thrombolyse him. He was thrombolysed with STK and review Echocardiography revealed improved Right ventricular functions and reduced Pulmonary artery pressures. Now he is doing well on folic acids, NOAC (dabigatran) ${ }^{8}$ and on regular follow up in hospital.

\section{Conclusion}

Syncope can be one of the presentations of pulmonary embolism without being associated with other symptoms. Syncope should be evaluated carefully and pulmonary embolism should be suspected as a differential diagnosis as it is a lifethreatening condition with considerable high mortality and should be recognized early.

\section{Conflict of interest}

The authors do not have any conflict of interest including financial in publication of this article.

\section{Reference:}

1. Thames MD, Alpert JS, Dalen JE. Syncope in patient with pulmonary embolism. JAMA 1977:238[23]:2509-11. https://doi.org/10.1001/jama.1977.03280240055020

2. Mor PurgoM, Zonzin P. Syncope in acute pulmonary embolism.2004 [1]:3-5

3. Calvo-Romero JM, Perez- MirindaM, Bureo-dacal P. Syncope in acute pulmonary embolism.2004:11[4]:208-9.

4. Ferrari E, Baudouy $M$, Cerboni P, etal. Clinical epidemiology of venous thromboembolism disease. EUR HEART J 1997:18[4]:685-91

https://doi.org/10.1093/oxfordjournals.eurheartj.a015316

5. Jenab Y, Lotfi-Tokaldany M, Alemzadeh-Ansari MJ, et al. Correlates of Syncope in Patients with Acute Pulmonary Thromboembolism. Clinical and Applied Thrombosis/ Homeostasis 2015:21(8):772-6.

6. Mahajan VS, Jarolim P. How to interpretate elevated cardiac troponin levels. Circulation2011:124[21]:2350-4. https://doi.org/10.1161/CIRCULATIONAHA.111.023697

7. Heijer D, Gerrits M, Haak WBJ, et al. Is hyperhomocysteinaemia a risk factor for recurrent venous thrombosis? Lancet 1995:345(8954): 882-57.

https://doi.org/10.1016/S0140-6736(95)90008-X

8 National Institute for Health and Care Excellence [webpage on the Internet] Dabigatran Etexilate for the Treatment and Secondary Prevention of Deep Vein Thrombosis and/or Pulmonary Embolism. 2014. [Accessed June 25, 2018]. 